data suggests a difficulty in maintaining improved screening rates and therefore we will need, in addition to the 4AT, strategies to ensure consistent increased screening rates.

\section{P-104 CHC FAST TRACK FUNDING: WHO, WHAT, WHEN?}

Caroline Hart, Alice O'Connor, Lynn Davies. Severn Hospice, Shropshire, UK

10.1136/bmjspcare-2018-hospiceabs.129

Background NHS Continuing healthcare [CHC] is the name given to funding of care which is arranged and funded solely by the NHS for individuals outside of hospital who have ongoing health care needs; the 'fast track CHC pathway' is a tool to enable the immediate provision of this care for patients who are deteriorating rapidly or who are actively dying (NHS Website). There is no timeframe for prognosis in the National Framework when considering eligibility for NHS Fast Track Funding.

Aims To review diagnostic trends in patients referred for fast track funding, the appropriateness of applications made by the hospice community team and the impact on place of death.

Method We recorded all fast track CHC funding requests made by the hospice community team between 1st June 2017 and 31st May 2018, recording date of request, date of death, place of death and diagnosis. We compared this to the whole population of patients referred to the service in that time.

Results 71 patients had a fast track $\mathrm{CHC}$ funding request made. 68 had a cancer diagnosis. 63 have died. Of those who have died, the range [in days] from application to death was 1-109 days. 36 [57\%] died within two weeks of the application, and four were still alive at 12 weeks. 36 died at home, 17 in the hospice inpatient unit, three in an acute hospital, one in a community hospital and six in a nursing home.

Conclusions and discussion When compared with our annual data, more patients died at home [57\% vs 44\%] and fewer died in hospital [6\% vs $17 \%$ ]. Nearly all of the patients had died within 12 weeks [the standard review period] indicating an excellent assessment of likely prognosis. However, with over half dying within two weeks of completing the request this raises the question: should we be requesting funding earlier?

\section{P-105 DEVELOPMENT OF A SINGLE ASSESSMENT PROCESS FOR INITIAL PATIENT CONTACT WITH A HOSPICE}

Emma Frampton, Becky Avery. Dorothy House Hospice Care, Winsley, UK

10.1136/bmjspcare-2018-hospiceabs. 130

Background Feedback from patients indicated that they were often seen by multiple different people after referral to the hospice, with duplication of processes. To address this, the hospice wanted to develop a 'single point of access' for patients and clients, to reduce duplication and provide more co-coordinated care for our patients. Part of this included developing a single assessment form for initial patient contact with the hospice.

Aim The primary aim was to develop a single assessment process for patients for their first point of contact with the hospice, in order to streamline and improve patient care and experience.
Methods A 'task to finish' group was set up in February 2017 to review the hospice referral form, and develop a single assessment process to be used for patient referrals. The group consisted of representatives from different departments within the hospice, including an independent group member from Healthwatch and a critical friend. A new referral form was developed with basic demographic details, including patient consent, any safety concerns, and six main questions (an initial question of 'what has prompted you to phone today' and questions covering physical, social, psychological, spiritual and functional domains). After a successful pilot with several local GP surgeries, and hospital nurse specialists, it was introduced to all referrers in April 2018. Referrals now come in to a dedicated co-ordination centre via telephone, email or the electronic notes system.

Results Feedback about the new referral form has been good. Referral information is of a higher quality, particularly for telephone referrals. The process for patients is more streamlined with less duplication.

Conclusion Higher quality information is obtained from the referrer, which supports MDT decision making over who is the most appropriate first point of contact. Patient experience of the hospice is improved.

\section{P-106 RECOGNISING DISTRESS AND BODILY CHANGES IN THE LAST HOURS OR DAYS OF LIFE}

Sharon Hill. Ashgate Hospicecare, Chesterfield, UK

\subsection{6/bmjspcare-2018-hospiceabs.131}

Background Between 56\%-74\% of the Great British public report their preference is to die at home (National Audit Office, 2008). Around half of all deaths occur in hospital although there are few clinical reason for admission, (National Audit Office, 2008; Berry, Brink, Harris et al., 2017) suggesting the need for greater community support to avoid inappropriate hospital admission.

Aims Ambitions for Palliative and End of Life Care (National Palliative and End of Life Care Partnership, 2015) set a framework for action; six ambitions to urge change at the end of life for individuals and those important to them to enable a good home death.

Method The leaflet guides them through symptoms which their loved one may experience. It offers education and practical information; helping the relative feel useful at a time when they perhaps feel helpless. The subjects cover those 'normal' symptoms considered to be the most distressing in the dying process.

Results The patient information leaflet will support and educate all those involved in the care of the dying person. The Community Palliative Care Specialist Nurse focus on prevention and relief of symptoms, in a prompt and timely manner to improve the quality of life for the patient and their family (World Health Organization, 2002). Continually assessing the signs and symptoms which may suggest that a person is in the last days of life will allow for compassionate and responsive care provision (NICE, 2015).

Conclusion There is scope for more people to die at home by improving training and understanding of end of life care needs. In May 2015, The Parliamentary and Health Service Ombudsman identified palliative care failings in the report 'Dying without dignity' suggesting that the ability of health 
professionals to recognise the dying person and responding to their needs was inconsistent.

\section{P-107 GOOD ENOUGH TO EAT: ENCOURAGING NUTRITIONAL INTAKE AND REAWAKENING APPETITE ON THE IN- PATIENT UNIT}

Nicola Hanmer, Tracy Parkinson. St Catherine's Hospice, Preston, UK

10.1136/bmjspcare-2018-hospiceabs. 132

Introduction A balanced diet and adequate fluid intake is important, especially for those with a life-shortening condition. In 2016 St Catherine's Hospice formed a Nutrition Focus Group, tasked with ensuring person-centred nutritional care for patients.

Aims To develop initiatives to increase food and fluid intake for patients. To re-awaken appetite in patients whose conditions have affected their desire to eat and drink. To widen choices. To modernise the presentation of meals, snacks and refreshments to better reflect the quality of dishes being served. To ensure meals, snacks and refreshments are served in an accessible way. To improve access to nutritious food for families 24/7. To promote the social element of sharing food and drink with loved ones.

Method We have made various improvements around three themes:

1. Food/drink/snacks. Extended choice on refreshments trolley to include filter coffee, fruit teas, fruit platters and smoothies. Continue to offer personalised choices alongside daily set menu. Continue to offer suggestions to those struggling to make food choices. Improved the variation in the pureed/soft foods menu

2. Accessibility. Invested in specialist equipment. Opened coffee bar in gift shop selling drinks, snacks and home-cooked ready meals 24 hours a day

3. Socialisation/normalisation. Invested in new trays and cutlery. Introduced linen napkins to improve the experience of having a meal and develop its sense of occasion. Refurbished the conservatory into a comfortable space where patients and loved ones can enjoy refreshments together. Invested in new moulds to improve the presentation of pureed/soft foods.

Evaluation Feedback is positive:

'My appetite has been dire for last 18 months and since being here has vastly improved', in-patient.

'Mum sometimes is not aware of what she wants so ideas are good', daughter of an in-patient.

\section{P-108 HYDRATION AT THE END OF LIFE: COLLABORATION AND EDUCATION TO EMBED CHANGE IN PRACTICE}

\footnotetext{
${ }^{1}$ Andrew Fletcher, ${ }^{2}$ Kathryn Woods, ${ }^{2}$ Louise Dowthwaite, ${ }^{1}$ Helen Jones, ${ }^{2}$ Stacey Batty, ${ }^{3}$ Claire Capewell. 'St Catherine's Hospice, Preston, UK; ${ }^{2}$ Lancashire Care Foundation Trust, Preston, UK; ${ }^{3}$ Lancashire Teaching Hospital NHS Trust, Preston, UK
}

\subsection{6/bmjspcare-2018-hospiceabs.133}

Background 'One chance to get it right' (Leadership Alliance for the Care of Dying People, 2014) and NICE guidance (National Institute for Health and Care Excellence, 2015) highlight the need to ensure appropriate means of providing hydration at end of life is available across care settings, including the availability of Clinically Assisted Hydration. Across our locality, the processes were not in place to achieve this and there was concern about understanding of the factors informing decision making.

Aims Develop procedure for the Administration of Subcutaneous Fluids in Adults at End of Life in the Community. Ensure robust mechanisms in place for monitoring management of hydration at end of life. Develop patient/carer information. Provide multi-professional education and training.

Methods Collaborative task and finish group established. Available literature reviewed to develop a patient/carer information leaflet. Multi-professional education and training package developed to enhance understanding of assessment and decision making.

Results Procedure for the Administration of Subcutaneous Fluids in Adults at End of Life in the Community was developed and agreed by our local community NHS Trust, hospice and clinical commissioning groups. Associated information contains a flowchart and other guidance. An audit proforma was developed to collect prospective data about the use and impact of subcutaneous fluids at end of life. A patient information leaflet was developed with agreement of partners. Multi-professional education and training was delivered to over 150 clinicians through attendance at GP training afternoons and hospice sessions (Macmillan grant funded).

Discussion A procedure has been agreed to ensure methods available to provide hydration support for patients at end of life, not limited by the place in which the person is being cared for. Feedback received from 89 attendees at the hospice education programme - score 1-6, 6 being excellent, 99\% of responders scored 5 or 6 ; $94 \%$ recommended the session. Qualitative feedback reflected the need for individualised assessments and staff feeling empowered to support patients.

\section{P-109 A MEAL TO DIE FOR}

Vera Mircescu. Mountbatten Hospice, Newport, UK

\subsection{6/bmjspcare-2018-hospiceabs.134}

Background Food is at the core of our existence and wellbeing. It provides familiarity and comfort, it brings families and friends together. In the context of palliative care, food choice can be seen as the sole opportunity for a patient to still make their own choices.

In our relentless pursuit to improve quality of life for our patients we identified the need to make food readily available to our patients throughout the day. Set meal times are not suited to the unpredictable nature of a hospice patient's daily schedule.

Aim To provide nutritious, tailor-made, enticing meals and drinks in the form of hotel room-service when our patients and their visiting families or friends want and need them. In addition to an á la carte menu we strive to meet any patient request for food, regardless of how difficult to source it may be.

Method Consultation meetings carried out with the medical teams. Á la carte menu created with nutritionist support. Food service trial sessions carried out involving patients, families and medical. Evaluation of food service trials. Patient survey carried out - feedback provided.

Results Improved patient nutrition as meal times were not missed. Increased patient satisfaction recorded as a result of 